\title{
Neurosciences Research
}

National Cancer Institute

\section{Source}

National Cancer Institute. Neurosciences Research. NCI Thesaurus. Code C15964.

Investigations in the disciplines concerned with the nervous system. 